\title{
Music as Water: \\ The Functions of Music from a Utilitarian Perspective
}

\author{
Liam Maloney \\ University of York, UK \\ Imaloney@gmail.com
}

Received 21 March 2017; accepted 26 September 2017; published 21 November 2017.

\begin{abstract}
The rapid increase of technologically enhanced listening platforms gives listeners access to music with ever-increasing ease and ubiquity, giving rise to the suggestion that we should now conceptualize music as a resource similar to water; something that is utilized to achieve everyday goals. This paper proposes that music is a utilitarian resource employed by listeners to augment cognitive, emotional, behavioral, and physiological aspects of the self. To better explore these notions this paper examines the potential role of the "functions of music," first espoused by Alan P. Merriam in 1964. Merriam suggested music has a situational use and an underlying function (music's ability to alter the self through listening).

The research presented here asserts that listeners interact with specific musical materials to achieve or orientate themselves towards contextually-rooted goals. Reinforcing Tia DeNora's suggestion that music is a "technology of the self" this research presents the results of a 41 publication meta-analysis exploring the possible functions of music. The resultant Aggregate Thematic Functions Framework (ATF framework) identifies 45 possible utilitarian functions of music, spread across five domains of action. The framework also proposes a meta-domain and an emotional sub-domain.
\end{abstract}

Keywords: augmentation; functions; goal; listeningof music; regulation; resource; utilitarian. 


\section{Music as Water}

"Music can now be seen as a resource rather than merely as a commodity" (North, Hargreaves, \& Hargreaves, 2004, p. 42) from the perspective of the listener. North et al.'s stance is grounded in the psychological and sociological employment of music; they suggest that music is capable of performing useful functions for listeners. The utility of music has been highlighted in numerous studies, each illustrating music's potential to augment various aspects of the self: psychological (e.g., ChamorroPremuzic \& Furnham, 2007; Greasley \& Lamont, 2011; Laukka, 2007), emotional (e.g., Gantz, Gartenberg, Pearson, \& Schiller, 1978; Laiho, 2004; Sloboda, 2005), social (e.g., Bennett, 2015; Christenson \& Roberts, 1998; Laiho, 2004), and physiological (e.g., Juslin, Liljeström, Västfjäll, Barradas, \& Silva, 2008; Sloboda, 2005).

Alternatively, Kusek, and Leonhard (2005) echo the ideas of David Bowie (Pareles, 2002) by suggesting that, in the current climate, we should conceptualize music as a resource akin to water; a basic utility for all. They argue from an economic perspective that, for the music business to survive and thrive, music should be considered a household utility. These two views are not incompatible; rather they are complimentary and interrelated. The notion of water as something that has utility for us in everyday life (hygiene, survival, agriculture, etc.), and the notion of water as an economic model (subscription based) is entirely applicable when examining the current instantiation of music in everyday life. We should perceive listening from a utilitarian perspective.

DeNora (1999) referred to music as "a technology of the self" as it is a tool we use to augment facets of ourselves as listeners (social interaction, emotions, physiology, etc.). As a resource, music is also somewhat dependent on its transmission via technological mediums. The increasing reflexivity and portability of music listening devices "means that the choice to hear specific music can be exercised in more and more situations" (Sloboda, Lamont, \& Greasley, 2012, p. 1). Krause, North, and Hewitt (2014) suggest that music can become imbued with new functions for us, and that these new uses spring from the increasing ubiquity of music in the world. Yet, this adaptive behavior does not exist in a vacuum. Scherer and Zentner (2001) point to the potent interplay of music, situation, and individual factors when individuals utilize music to achieve specific outcomes. Further compounding the issue of listening is the omnipresent sonic landscape in which we live, with sound as an increasingly pervasive force in retail establishments, restaurants and bars, television, associated media, recreation, etc. often occurring in direct opposition to our desired listening material or use of said materials. To fully understand the current state of utilitarian listening we must begin by facing two questions: firstly, how has our listening shifted over time with new technologies? Secondly, what functions can music perform for us?

The first of these questions is far too nuanced and wide-ranging to explore in this short paper. Some progress has been made (i.e., Sterne, 2003), but much of our engagement remains obfuscated or unmapped. Rather, this paper is concerned with 
the second question. Whether we are aware or not of the potential ramifications music can have on the psychological, emotional, social, and physiological aspects of life (e.g., Knobloch \& Zillmann, 2002; Saarikallio, 2011), it is a resource we employ on an everyday basis. Thus, this resource has innate functionality we can draw on. Arguably, music has always served functions for us but, with the growing technological refinement with which we listen, the potential for music to serve utilitarian functions has increased. Therefore, what functions does music serve and how can we begin to identify them?

\section{Uses and Functions}

Use then, refers to the situation in which music is employed in human action; function concerns the reasons for its employment and particularly the broader purpose which it serves (Merriam, 1964, p. 210).

Alan P. Merriam was the first to suggest, define, and model the functions music could serve within a society. He explicitly created a divide between use, as being related to the situation, and function as the underlying rationale relating to the desired effect of the music. Andrew H. Gregory (1997) is one of the few researchers to strictly adhere to Merriam's original definitions and points to several examples of music use grounded in the situational or contextual aspects of music's employment: lullabies, battle, games, etc. Function, however, has generated far more interest in academic research, with many researchers proposing their own model of the functions of music. Merriam was the first to identify functions of music constructed from anthropological and ethnomusicological study, 10 in total: emotional expression, aesthetic enjoyment, entertainment, communication, symbolic representation, physical response, and four functions concerning social institutions and social stability).

Hargreaves and North (1999) attempted to re-evaluate Merriam's original model for the contemporary Western society, placing the emphasis on the social aspects of music (adding concepts related to self-identity, interpersonal relationships, and mood management). DeNora (2000) drew her own suggested framework that related to specific domains of action (the body, situations, communication, etc.), domains that are also reflected in the work Sloboda et al. (2012). Bull (2000) and Williams (2006) both performed work into the functions of portable music in contemporary Western society. Numerous other models also exist within the literature but there is currently no consensus as to the functions of music.

It should be noted that there exists no comparative analysis of functions from a historical perspective, and little is known about how functions may have changed over time as a result of technological or social change. Given the questions raised in the previous section, this further level of inquiry is not feasible owing to the interdependency of these concepts. 


\section{Aggregate Thematic Functions Framework}

Given the variety and variation between the functions presented in the corpus of the literature, the following analysis attempts to identify an exhaustive list of the potential functions of music, and group them by domain of action (cognitive, emotional, physiological, social group, social individual). The analysis then provides a visual representation of the framework, suggesting possible interconnected functions, one meta-domain, and one sub-domain.

\section{Literature Search}

The search for salient literature was conducted using electronic academic databases. Using multiple keywords, the aim was to gather the broadest range of possible literature dealing with the functions of music. Keywords included: function, music, use, regulation, strategy, and listening. Pluralized terms were also used. The term use was specifically included to overcome the misidentification of function by many researchers. There were no date restrictions placed upon the search. Articles that replicated the work of prior researchers, without alteration, were excluded to remove redundancy.

\section{Methodology}

Publications were partially drawn from Schäfer, Sedlmeier, Städtler, and Huron's analysis (2013). Additional studies were identified from literature searches and references therein. 41 publications were identified in total. The publications draw from a broad range of disciplines (see Figure 1): music psychology and sociology represent over half of the body of papers (58\%). Other areas include musicology, music and emotion, and music in everyday life. Sports sciences was the least frequent discipline (only one publication was identified). Few papers differentiate between recorded music listening and live music listening. This lack of differentiation shall be maintained here.

10 publications included multiple datasets. Where applicable, these are included and treated as discrete entities. Across the 41 publications 58 datasets were identified.

620 references to the functions of music were identified. 18 functions were labeled as "incorrect," as they did not adhere to Merriam's definition (the findings were in fact either use or descriptions of musical aesthetics). These were excluded from the analysis. The remaining 602 functions were then sorted into five domains of action (psychological, emotional, physiological, social individual, and social group) based on their description within the original source publication. Finally, the identified functions within each domain were combined based on their description in the original source publication and semantic coherence using NVivo software. 


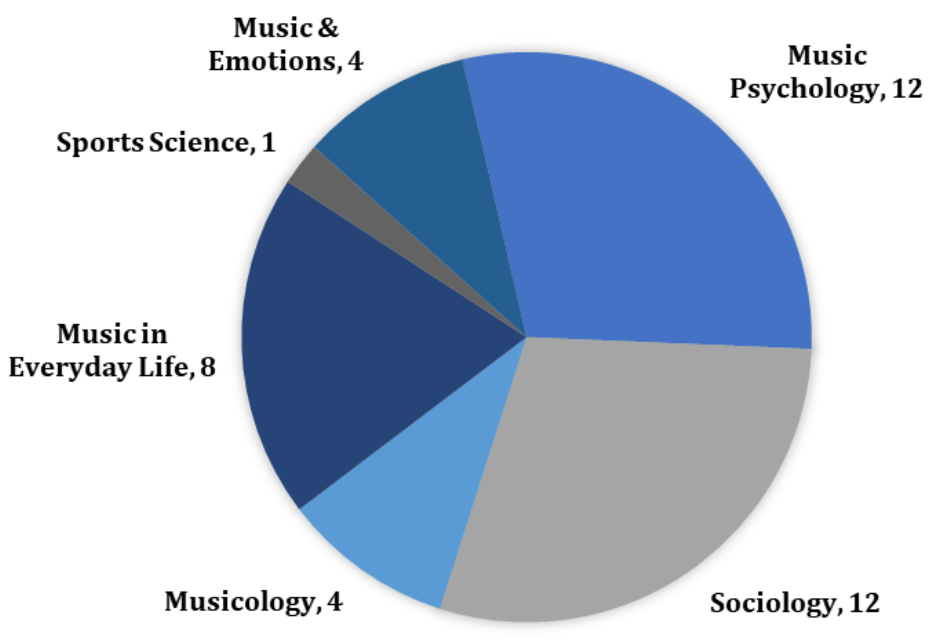

Figure 1. Paper distribution by discipline.

\section{Results}

The emotional domain of function was the most frequent within the aggregate body of functions: 158 instances of emotional functions (26\% of total functions). The least frequent was the social individual domain of functions: 45 instances (7\% of total functions). The social group domain accounts for more than three times that of social individual with 136 functions identified (23\%). Cognitive functions and physiological functions also occurred with relatively high frequency (22\% and $21 \%$ respectively). N.B. percentages are to the nearest integer.

Regarding the publications and individual datasets, social group was the most common domain of functionality: 45 of the 58 datasets within the aggregate body contained at least one function pertaining to the social group domain. Conversely, the social individual domain was the least frequent: occurring in only 24 of the 58 datasets. The threefold increase is not represented here, rather an approximate doubling between social individual and social group functions. This implies that whilst there are fewer functions overall pertaining to the social individual domain, this is not representative of how likely an article is to contain social individual function.

Analysis identified Christenson \& Roberts (1998) as the most function-rich study, presenting 39 individual references to function. Two datasets did not yield any valid functions: Hargreaves \& North (1999) $A$, and Packer \& Ballantyne (2010) B. Functions were not weighted by citation count or impact factor of the source article. 
The thematic semantic grouping of functions revealed 45 functions of music spread across the various domains. Five functions appeared within multiple domains, these were mapped to the meta-domain. Within emotional functions, there appeared a group of five interrelated functions. These were compiled into a sub-domain: specific regulatory strategies.

\section{Findings \& Discussion}

45 discrete functions were uncovered in the Aggregate Thematic Functions Framework (hereafter referred to as ATF framework; see Figure 2) and were sorted into five domains of action. Two additional domains were also included for clarity (the meta-domain and the specific regulatory strategies sub-domain). The frequency of each function within the aggregate dataset is shown, and the total aggregate references within a domain is shown with the domain title. The meta-domain and emotional specific regulatory strategies sub-domain also include frequency.

The most function-rich domain in the ATF framework is the physiological domain, presenting 10 distinct functions, and the social individual domain is the least function-rich area, only offering 5 functions. Some functions were found in multiple domains, e.g., "Create \& Maintain Atmosphere." These functions act on multiple domains simultaneously, and are hence grouped in the meta-domain, with the appropriate apportionment of references included. The emotional functions of music also showed a distinct subset of functions related to the directionality of emotional regulation: "Accentuation," "Change," "Convey," "Regulating," or "Triggering." These appear somewhat different from other emotional functions and refer directly to the specific emotional orientation an individual may desire from listening behaviors.

The most frequent domain-specific function was that of "Interaction \& Bonding" (in the social group domain), occurring 47 times within the aggregate body. This function is concerned with "socialising" and "belonging" (Bennett, 1999), "social utility" (Laiho, 2004), and "social actualisation" (Packer \& Ballantyne, 2010). The function concerns individuals using music within group scenarios as a means to establish and maintain interpersonal relationships. Other highly frequent functions include "Accompaniment" (employing music to do something to or to accompany mundane activities) in the physiological domain, "Distraction" (employing music to occupy unused attention during tasks or to avoid other thoughts/feelings) in the cognitive domain, and "Regulate or Maintain Emotion/Mood" in the emotional specific regulatory strategies sub-domain (using music to maintain a specific level or arousal or emotion/mood). 


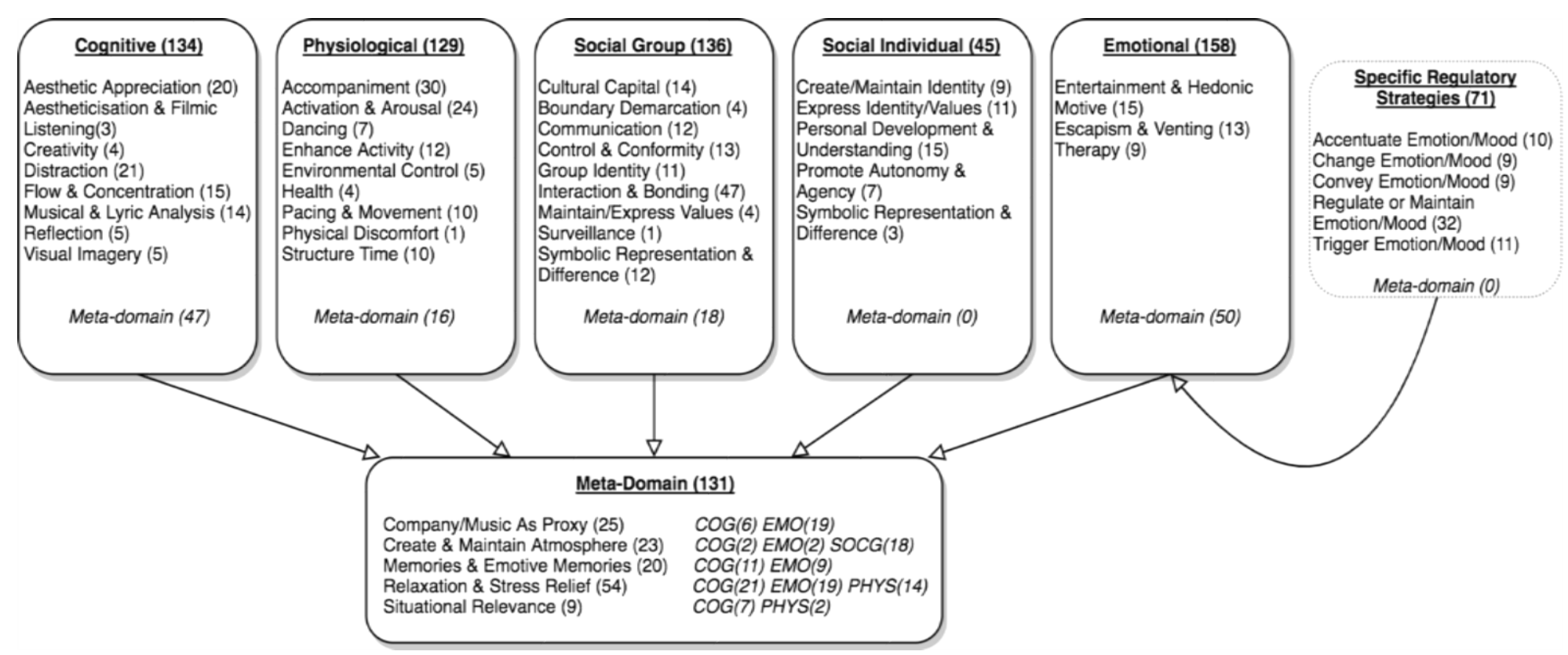

Figure 2. Aggregate Thematic Functions Framework 
A caveat should be noted here. Whilst the ATF framework shows frequency of terms in the body of research, the data does not necessarily equate to the frequency of these functions in "real world" scenarios. Although a function occurs frequently in the literature, it is feasible this function occurs with relative infrequency in everyday listening episodes. The inverse could also be true: low frequency in research but high frequency of employment in real world situations.

The proposed meta-domain has certain inferences for the functions of music. It would appear to support the findings of Greasley and Lamont (2011): "People choose to listen to music to fulfil different functions simultaneously" (p. 63). Given that individuals use music to achieve multiple functions simultaneously (Greasley and Lamont stated an average of three functions per listening episode), the meta-domain may be an expression of this. "Relaxation" functions may occur in several domains simultaneously. It is also feasible that some functions resonate with one another. "Relaxation \& Stress Relief" would certainly have implications for functions surrounding physiological arousal and emotional regulatory functions. In addition, it may be true that some functions, hypothetically at least, are mutually exclusive. It is unlikely that "Escapism \& Venting" and "Flow \& Concentration" functions could occur in tandem. However, from this analysis, it is not possible to identify which functions are used simultaneously, or which are in direct opposition to one another.

\section{Conclusions}

The ATF framework exhausts the possibilities presented in the available literature. It also proposes a domain-based conceptualization of function. However, it is possible that there are further functions of music that have yet to be uncovered, or possibly even other domains of action that have not yet been identified. Given our increasing technological augmentations of the self through listening, it is possible that new functions may appear over time.

Scherer and Zentner's (2001) assertion that the functions of music are grounded in contextual and personal factors remains a problematic concept. There is little research that attempts to identify which contexts give rise to which functions, and furthermore, which musical features are most conducive to actualizing which functions. The notion of mapping both musical features and situational factors atop the functions identified here is a daunting one. Some work has mapped musical features to emotional responses (cf. Gabrielsson \& Lindström, 2001), although few have explored the other domains of action beyond the emotional.

Finally, this analysis aims to present a strong case for Merriam's (1964) original definitions. The confusion and variation in definition across the functions literature only hinders the search for functions. Often, we see use (the situational aspects), the underlying physiological mechanisms, and even the effects of music listening branded 
incorrectly as function. Without adhering to the tenets of Merriam (or a newly constructed and widely accepted definition), it is unlikely this misattribution and resultant confusion of the concept of function will be resolved.

A utilitarian conceptualization of musical function may allow listeners to develop new methods of listening and active participation when augmenting aspects of the self. Just as water is a functional and ubiquitous resource, music, understood in this way, may present a readily accessible and ubiquitous resource for augmentation of the self.

\section{Acknowledgments}

Special thanks to Sue Denham, John Matthias, Jess Rymer, and Hannah Drayson for their thoughtful and insightful feedback in developing this paper.

NB: References for publications used in the ATF analysis are available on request.

\section{References}

Bennett, A. (1999). Subcultures or neo-tribes? Rethinking the relationship between youth, style and musical taste. Sociology, 33(3), 599-617. doi:10.1177/S0038038599000371

Bennett, A. (2015). Identity: Music, community and self. In J. Shepherd \& K. Devine (Eds.), The Routledge Reader on The Sociology of Music (pp. 143-151). New York, NY: Routledge. doi:10.4324/9780203736319

Bull, M. (2000). Sounding out the city: Personal stereos and the management of everyday life. London: Bloomsbury Adacemic. doi:10.5040/9781474215541

Chamorro-Premuzic, T., \& Furnham, A. (2007). Personality and music: Can traits explain how people use music in everyday life? British Journal of Psychology, 98(2), 175-185. doi:10.1348/000712606X111177

Christenson, P. G., \& Roberts, D. F. (1998). It's not only rock \& roll: Popular music in the lives of adolescents. Cresskill, NJ: Hampton Press.

DeNora, T. (1999). Music as a technology of the self. Poetics, 27(1), 31-56. doi:10.1016/S0304422X(99)00017-0

DeNora, T. (2000). Music in Everyday Life. Cambridge, UK: Cambridge University Press. doi:10.1017/cbo9780511489433

Gabrielsson, A., \& Lindström, E. (2001). The influence of musical structure on emotional expression. In P. N. Juslin \& J. A. Sloboda (Eds.), Music and emotion: Theory and research (pp. 223-248). Oxford, UK: Oxford University Press.

Gantz, W., Gartenberg, H. M., Pearson, M. L., \& Schiller, S. O. (1978). Gratifications and expectations associated with pop music amongst adolescents. Popular Music and Society, 6(1), 81-89. doi:10.1080/03007767808591113 
Greasley, A. E., \& Lamont, A. (2011). Exploring engagement with music in everyday life using experience sampling methodology. Musicae Scientiae, 15(1), 45-71. doi:10.1177/1029864910393417

Gregory, A. H. (1997). The roles of music in society: the ethnomusicological perspective. In D. J. Hargreaves \& A. C. North (Eds.), The social psychology of music (pp. 123-140). Oxford, UK: Oxford University Press.

Hargreaves, D. J., \& North, A. C. (1999). The functions of music in everyday life: Redefining the social in music psychology. Psychology of Music, 27(1), 71-83. doi:10.1177/0305735699271007

Juslin, P. N., Liljeström, S., Västfjäll, D., Barradas, G., \& Silva, A. (2008). An experience sampling study of emotional reactions to music: Listener, music, and situation. Emotion, 8(5), 668-683. doi:10.1037/a0013505

Knobloch, S., \& Zillmann, D. (2002). Mood management via the digital jukebox. Journal of Communication, 52(2), 351-366. doi:10.1093/joc/52.2.351

Krause, A., North, A. C., \& Hewitt, L. (2014). Music selection behaviors in everyday listening. Journal of Broadcasting \& Electronic Media, 58(2), 306-323. doi:10.1080/08838151.2014.906437

Kusek, D., \& Leonhard, G. (2005). The future of music: Manifesto for the digital music revolution. S. G. Lindsay (Ed.). Boston, MA: Berklee Press .

Laiho, S. (2004). The psychological functions of music in adolescence. Nordic Journal of Music Therapy, 13(1), 47-63. doi:10.1080/08098130409478097

Laukka, P. (2007). Uses of music and psychological well-being among the elderly. Journal of Happiness Studies, 8(2), 215-241. doi:10.1007/s10902-006-9024-3

Merriam, A. P. (1964). The anthropology of music. Evanston, IL: Northwestern University Press.

North, A. C., Hargreaves, D. J., \& Hargreaves, J. J. (2004). Uses of music in everyday life. Music Perception, 22(l), 41-77. doi:10.1525/mp.2004.22.1.41

Packer, J., \& Ballantyne, J. (2010). The impact of music festival attendance on young people's psychological and social well-being. Psychology of Music, 39(2), 164-181. doi:10.1177/0305735610372611

Pareles, J. (2002, June 9). David bowie, 21st-century entrepreneur. The New York Times. New York. Retrieved from http://www.nytimes.com/2002/06/09/arts/david-bowie-21stcentury-entrepreneur.html

Saarikallio, S. (2011). Music as emotional self-regulation throughout adulthood. Psychology of Music, 39(3), 307-327. doi:10.1177/0305735610374894

Schäfer, T., Sedlmeier, P., Städtler, C., \& Huron, D. (2013). The psychological functions of music listening. Frontiers in Psychology, 4. doi:10.3389/fpsyg.2013.00511

Scherer, K. R., \& Zentner, M. R. (2001). Emotional effects of music: Production rules. In P. N. Juslin \& J. A. Sloboda (Eds.), Series in affective science. Music and Emotion: Theory and Research (pp. 361-392). Oxford, UK: Oxford University Press. 
Sloboda, J. A. (2005). Everyday uses of music listening: A preliminary study. In J. A. Sloboda (Ed.). Exploring the musical mind: Cognition, emotion, ability, function (pp. 319-331). Oxford, UK: Oxford University Press. doi:10.1093/acprof:oso/9780198530121.003.0018

Sloboda, J. A., Lamont, A., \& Greasley, A. (2012). Choosing to hear music. In Oxford Handbook of music psychology (pp. 1-11). Oxford, UK: Oxford University Press. doi:10.1093/oxfordhb/9780199298457.013.0040

Sterne, J. (2003). The audible past: Cultural origins of sound reproduction. Durham, UK: Duke University Press. doi:10.1215/9780822384250

Williams, A. (2006). Portable music \& its functions. New York, NY: Peter Lang Publishing. 